\title{
CONTROLE DE PLANTAS DANINHAS NA CULTURA DO ARROZ DE SEQUEIRO (Oryza sativa L.)
}

\section{RESUMO}

Com o objetivo de verificar o controle de plantas daninhas com herbicidas na cultura do arroz de sequeiro, foi conduzido o presente experimento em um latossolo roxo, série Jaboticabal com $4,82 \%$ de m.o, utilizando-se a variedade Pratão Precoce.

Foram utilizados os seguintes tratamentos com as respectivas doses em $\mathrm{kg}$ do i.a/ha: pendimethalin a $0,75,1,00$ e 1,50; AC-92390 a 1,00, 2,00 e 3,00 ; butachlor a 2,05 ; benthiocarb a 4,50 ; oxadiazon a 1,0 todos em pré emergência; e propanil a 4,32; propanil $+2,4-\mathrm{D}$ amina a $2,88+0,36$ e propanil + parathion metílico a $1,98+0,24$, em pósemergência aos 29 dias após o plantio.

As plantas daninhas que ocorreram em maior densidade foram: carrapicho-de-carneiro (Acanthospermum hispidum D.C.), trapoeraba (Commelina sp.), falsa-dormideira (Cassia patellaria D.C.), anileira (Indigofera hirsuta L.), capimcarrapicho (Cenchrus echinatus L.), beldroega (Portulacca oleracea L.) e guanxuma (Sida sp.). O carrapicho-de-carneiro só foi controlado pelos tratamentos em pós-emergência; a falsa-dormideira pelo butachlor e pelos tratamentos em pós-emergência. No controle geral os melhores indices foram obtidos com os tratamentos em pós-emergência. Os tratamentos em pré-emergência foram capinados aos 36 dias após o plantio devido ao baixo controle do carrapicho-de-carneiro, e os de pós-emergência aos 54 dias devido ao baixo controle da trapoeraba. Quanto à fitotoxicidade à cultura o tratamento propanil + parathion metflico atingiu fitotoxicidade qu ase forte (nota 5,8 ) pela escala E.W.R.C., todavia não houve diferenca significativa entre os diferentes tratamentos com herbicida na produção de grãos.

PALAVRAS-CHAVE: herbicidas, arroz de sequeiro, interação herbicida $\mathrm{x}$ inseticida.

\section{R. VICTORIA FILHO* \& J.B. CARVALHO**}

* Prof. Assistente Doutor - Dep. de Agricultura e Horticultura - ESALQ-USP. C.P. 9 - 13400 Piracicaha - SP

** Ex-Estagiário da Fac. de Ciências Agrárias e Veterinárias - "Campus" de Jaboticabal.

\section{SUMMARY \\ WEED CONTROL IN UPLAND RICE (ORYZA SATIVA L.)}

A field trial was performed, on a oxisol (Latos solic B) containing $4.82 \%$ organic matter, with the objetive to verify the weed control with pre and postemergence herbicides in upland rice cv "Pratão Precoce".

The following treatments were used (kg a.i/ ha): pendimethalin at $0,75,1,00$ and 1,50 ; AC-92390 at 1,00, 2,00 and 3,00; butachlor at 2,05; benthiocarb at 4,50; oxadiazon at 1,0 ; in pre-emergence and propanil at 4,32; propanil + 2,4-D amine at $2,88+0,36$, and propanil + parathion me thyl at $1,98+0,24$. in postemergence 29 days after planting.

The predominant weeds were: Acanthospermum hispidum D.C., Commelia sp, Cassia patellaria D.C, Indigofera hirsuta L., Cenchrus echinatus L., Portulacca oleracea L. and Sida sp.

Only the postemergence treatments control led Acanthospermum hispidum D.C, but Cassia patellaria D. 0 was controlled by butachlor and the postemergence treatments. The best total weed control were obtained by the postemergence treatments. The preemergence treatments were hoed at 36 days after planting and the postemergence treatments at 54 days. The treatment with propanil + parathion methyl presented fitotoxicity 5,8 by the EWRC scale, but there wasn't significative difference between the treatments with herbicides in grain yield.

KEY-WORDS: herbicides, upland rice, interaction herbicide $\mathrm{x}$ inseticide.

\section{INTRODUÇÃO}

A cultura do arroz de sequeiro é bastante difundida no Estado de São 
Paulo, cobrindo ampla faixa geográfica. As plantas daninhas causam prejuízos não só pela competição produzindo que da na produção que pode variar de 35 a $74 \%$, segundo Brandes (4), e de até $85 \%$, segundo Vega (15), mas, também por dificultarem muito as operações da colheita mecânica.

A utilização do controle químico na cultura do arroz de sequeiro tem sido problemático, devido principalmente, ao custo que representa à cultura, que normalmente é de baixa rentabilidade. Diversos herbicidas são recomendados para essa cultura, e dentre eles destaca-se o propanil $(7,8$ e 9), que muito embora apresente alguns sintomas de fitotoxicidade à cultura, esses danos parecem não se refletir na produção (5 e 6). Quando aplicado em mistura com alguns inseticidas, ou, a pequeno intervalo de tempo destes, tem apresentado sintomas mais severos de fitotoxicidade (3 e 5). Smith (13) cita que danos têm ocorrido quando o propanil é aplicado com inseticidas carbamatos ou fosforados, ao passo que misturas com hidrocarbonetos clorados não são prejudi ciais.

Oliveira (10) não observou efeito prejudicial ao arroz com mistura de propanil e o inseticida canfeno-clorado, nem com doses de $4,0 \mathrm{~kg}$ i.a/ha do propanil aplicado 2 a 4 dias após às aplicações dos inseticidas toxafeno e endrin nas doses de 1,5 e 1,2 1/ha do produto comercial respectivamente.

Revelo (11), na Colômbia, verificou incompatibilidade de aplicação conjun ta de propanil com inseticidas organofosforados ou carbamatos, e que essa incompatibilidade poderia ser eliminada mediante aplicações individuais com intervalos de uma semana.

Souza (14), através de estudos em casa de vegetação, utilizando diversas misturas de propanil com parathion metílico, chegou à conclusão de que a mistura de propanil + parathion metílico $(60 \%)$ a $2,00 \mathrm{~kg}+0,24 \mathrm{~kg}$ do ingrediente ativo por hectare pelo controle das plantas daninhas e pela tolerância das plantas de arroz foi considerada a mis tura mais econômica.

Com relação às misturas de propa nil $+2,4-\mathrm{D}$, os resultados têm sido bons
(2), permitindo diminuição na dose aplicada de propanil. O pendimethalin não tem apresentado injúrias à cultura de acordo com trabalho de Santos (12).

Portanto, o presente experimento foi conduzido procurando-se verificar o comportamento em condições de campo de misturas de propanil com $2,4 \mathrm{D}$ e com parathion metílico aplicados em pós-emergência, além de outros herbicidas aplicados em préemergência.

\section{MATERIAIS E MÉTODOS}

O experimento foi instalado na área experimental da Faculdade de Ciências Agrárias e Veterinárias "Campus" de Jaboticabal em um latossolo roxo, Série Jaboticabal, contendo $56,2 \%$ de argila e $4,82 \%$ de matéria orgânica. A variedade de arroz utilizada foi a "Pratão Precoce", sendo o plantio realizado a 23 de outubro de 1973 .

O delineamento experimental adotado foi o de blocos ao acaso com 14 tratamentos e 5 repetições. As parcelas constituíam-se de 10 linhas de $5,0 \mathrm{~m}$ de comprimento com espaçamento de $0,60 \mathrm{~m}$. Os tratamentos utilizados, com as respectivas doses do i.a e p.c./ha, encontram-se no quadro 1 . O herbicida AC-92390 (N-sec-butil-2,6-dinitro-3,4xylidine) é também uma dinitroanilina com fór mula estrutural bem semelhan te ao pendimethalin. Os herbicidas de pré-emergência foram aplicados no dia $25 / 10 / 73$, com temperatura de $25,7^{\circ} \mathrm{C}$ e umidade relativa do ar de $66 \%$. Os herbicidas de pós-emergência foram aplicados 29 dias após o plantio, quando as plantas de arroz estavam em média com duas fol has, a temperatura er a de $24^{\circ} \mathrm{C}$ e a umidade relativa de $53 \%$. 0 equipamento utilizado foi um pulverizador à pressão constante $\left(\mathrm{CO}_{2}\right)$ com três bicos Teejet 80.02 , à pressão de $2,81 \mathrm{~kg} / \mathrm{cm} "$ com um consumo de calda de 4001 / ha.

As avaliações foram realizadas através da contagem das plantas daninhas por espécie botânica em uma área de $1,6 \mathrm{~m}^{2}$ por parcela, correspondendo a $8,3 \%$ da área útil aos 36 dias após o 
Quadro 1. Tratamentos utilizados com as respectivas doses do Ingrediente ativo (i.a.) e produto comercial (p.c) por hectare, e época da aplicação.

\begin{tabular}{|c|c|c|c|}
\hline \multirow{2}{*}{ TRATAMENTOS } & \multicolumn{2}{|c|}{ DOSES } & \multirow{2}{*}{$\begin{array}{l}\text { EPOCAS DE } \\
\text { APLCAÇĀo }\end{array}$} \\
\hline & $\log 1.4 . / h$ & kg ou 1 p.c/ha & \\
\hline $\begin{array}{l}\text { 1. Test. sem capina } \\
\text { 2. test. com capina } \\
\text { 3. pendimethalin } \\
\text { 4. pendimethallin } \\
\text { 5. pendimethalin } \\
\text { 6. AC-92390 } \\
\text { 7. AC-92390 } \\
\text { 8. AC-92390 } \\
\text { 9. butachlor } \\
\text { 10. benthiocarb } \\
\text { 11. oxadiazon } \\
\text { 12. propanil } \\
\text { 13. propanil + 2,4-D } \\
\text { 14. propanil + parathion metilioo }\end{array}$ & $\begin{array}{c}0,75 \\
1,00 \\
1,50 \\
1,00 \\
2,00 \\
3,00 \\
2,05 \\
4,50 \\
1,00 \\
4,32 \\
2,88+0,36 \\
1,98+0,24\end{array}$ & $\begin{array}{c}2,20 \\
3,00 \\
4,50 \\
2,50 \\
5,00 \\
7,50 \\
5,00 \\
9,00 \\
4,00 \\
12,00 \\
8,0+0,5 \\
5,5+0,4\end{array}$ & $\begin{array}{l}\text { pré-emegêncla } \\
\text { pré-emergêncla } \\
\text { pré-emergência } \\
\text { pré-emergência } \\
\text { pré-emergência } \\
\text { pré-emergêncla } \\
\text { pré-emergência } \\
\text { pró-emergência } \\
\text { pré-emergência } \\
\text { pós-emergência } \\
\text { pós-emergência } \\
\text { pós-emergência }\end{array}$ \\
\hline
\end{tabular}

plantio e uma avaliação visual através da Escala do Conselho Europeu de Pesquisas sobre Plantas Daninhas (EWRC), aos 47 dias após o plantio. No final do ciclo foram colhidas as oito linhas centrais de quatro metros de comprimento para avaliação da produção.

\section{RESULTADOS E DISCUSSÃO}

Os dados do número das plantas daninhas que ocorreram em maior densidade, assim como as porcentagens de controle em relação à testemunha sem capina encontram-se no Quadro 2. No número total estão incluídas outras plantas daninhas que ocorreram na área experimental.

Com relação ao carrapicho-de-carneiro, somente os tratamentos em pósemergência apresentaram um controle aceitável $(77,5 \%)$. Por outro lado com relação à falsa-dormideira, além dos tratamentos em pós-emergência, também o tratamento com butachlor em pré-emergência apresentou controle acima de $90 \%$. A beldroega foi melhor controlada pelos tratamentos em préemergência.

No controle total das plantas daninhas presentes verifica-se que os indi- ces de controle são baix os, com exceção dos tratamentos pós-emergentes que controlaram bem o carrapicho-de-carneiro e a falsa-dormideira, que foram as plantas daninhas que ocorreram em maior densidade.

Os dados do controle de plantas daninhas e fitotoxicidade à cultura aos 47 dias após o plantio, através da escala EWRC, encon tram-se no Quadro 3.

Verifica-se por essa avaliação visual aos 47 dias que, concordando com os dados de percentagem de controle, os melhores tratamentos foram aqueles aplicados em pós-emergência. Salientase a fitotoxicidade entre média e quase forte causada pelo tratamento de propanil + parathion metílico, fato também observado por SOUZA (14) em condições de casa-de-vegetação. Já a fitotoxicidade causada pelos tratamentos de propanil e propanil + 2,4-D foram leves, concordando com resultados de Hudgins (6), French e Gay (5), Leiderman et al. (8), Bhan et al. (2) e Mangoensoekardjo e Kadnan (9).

Os resultados da produção de grãos dos diferentes tratamentos encon tramse no Quadro 4. Verifica-se que todos os tratamentos diferiram da testemunha sem capina. O tratamento de propanil + parathion metílico, muito embora com sintomas fitotóxicos atin- 
Quadro 2. Porcentagem de controle das plantas daninhas que ocorreram em maior densidade na área experi mental

\begin{tabular}{lccccc}
\hline \hline TRATAMENTOS & $\begin{array}{c}\text { DOSE } \\
\text { kg ia/ha }\end{array}$ & $\begin{array}{c}\text { carrapicho- } \\
\text { de-carnetro } \\
\%\end{array}$ & $\begin{array}{c}\text { fals dormi- } \\
\text { deira } \%\end{array}$ & Beldroeg \% & total \% \\
\hline 3. pendimethalin & 0,75 & 39,7 & 74,3 & 83,3 & 47,5 \\
4. pendimethalin & 1,00 & 5,3 & 64,4 & 98,7 & 33,4 \\
5. pendimethalin & 1,50 & 22,6 & 8,3 & 90,7 & 5,6 \\
6. AC-92390 & 1,00 & 9,9 & 38,1 & 85,3 & 0,0 \\
7. AC-92390 & 2,00 & 30,5 & 49,5 & 96,0 & 35,6 \\
8. AC-92390 & 3,00 & 25,8 & 37,6 & 86,7 & 24,1 \\
9. butachlor & 2,05 & 24,5 & 93,3 & 71,3 & 37,2 \\
10. benthiocarb & 4,50 & 16,6 & 0,0 & 96,0 & 0,0 \\
11. oxadiazon & 1,00 & 29,6 & 0,0 & 98,7 & 4,1 \\
12. propanil & 4,32 & 77,0 & 100,0 & 73,3 & 78,1 \\
13. propanil + 2,4-D & $2,88+0,36$ & 90,7 & 92,8 & 69,3 & 84,1 \\
14. propanil + parathion metilico & $1,98+0,24$ & 86,8 & 100,0 & 52,0 & 84,1 \\
test. sem capina & - & $23,6 \mathrm{pl} / \mathrm{m}^{2}$ & $30,3 \mathrm{pl} / \mathrm{m}^{2}$ & $11,7 \mathrm{pl} / \mathrm{m}^{2}$ & $57,8 \mathrm{pl} / \mathrm{m}^{2}$ \\
\hline \hline
\end{tabular}

Quadro 3. Reaultados da avallaço vieuel reallzeda 47 dias apbe o plantio pela eecala EWRC*

\begin{tabular}{|c|c|c|c|}
\hline TRATAMENTOS & DOSE $\mathbf{i} \mathbf{a} / \mathbf{k g} / \mathbf{h a}$ & CONTROLE & FITOTOXICIDADE \\
\hline testemunha & - & 9 & 1 \\
\hline 3. pendimethalin & 0,75 & 4,4 & 1 \\
\hline 4. pendimethalin & 1,00 & 4,2 & 1 \\
\hline 5. pendimethalin & 1,50 & 4,4 & 1 \\
\hline 6. AC -92390 & 1,00 & 4,6 & 1 \\
\hline 7. AC- 92390 & 2,00 & 4,4 & 1 \\
\hline 8. AC- 92390 & 3,00 & 4,6 & 1 \\
\hline 9. butachlor & 2,05 & 5,0 & 1 \\
\hline 10. benthiocarb & 4,50 & 5,2 & 1 \\
\hline 11. oxadiazon & 1,00 & 4,0 & 1 \\
\hline 12. propanil & 4,32 & 2,4 & 3,8 \\
\hline 13. propanil $+2,4-D$ & $2,88+0,36$ & 2,2 & 2,6 \\
\hline 14. propanil + parathion metílico & $1,98+0,24$ & 2,8 & 5,8 \\
\hline
\end{tabular}

gindo a nota 5,8 pela escala $\mathrm{E} \mathrm{W} \mathrm{RC} \mathrm{aos}$ 18 dias após a aplicação, apresentou recuperação de tal modo que não apresentou diferença significativa com os outros tratamentos com herbicidas e também com a testemunha capinada, concordando com os resultados obtidos por Souza (14) em casa-de-vegetação. Todavia os sin tomas fitotóxicos podem se agravar, dependendo das condições ambientais, de tal modo que seria dificil uma recomendação desse tipo de mistura, pois diversos autores já constataram sintomas fitotóxicos às plantas de arroz com as aplicações em misturas (3 e 5), mas muitos deles não avalia ram os reflexos na produção. French e Gay (5) citam que inseticidas, fungicidas, fertilizantes líquidos não devem ser aplicados dentro de dez dias precedentes ou seguintes à aplicação de propanil, e Revelo (11) sugere aplicações individuais com intervalos de uma semana. Mas esse tipo de mistura, pro- 
Quadro 4. Produção de arroz em grãos nas oito linhas centrals de quatro metros de comprimento

\begin{tabular}{|c|c|c|}
\hline TRATAMENTOS & DOSE leg is/ha & PRODUÇÃO kg/ha \\
\hline $\begin{array}{l}\text { 1. test. sem capina } \\
\text { 2. test. com capina } \\
\text { 3. pendimethalin } \\
\text { 4. pendimethalin } \\
\text { 5. pendimethalin } \\
\text { 6. AC } 92390 \\
\text { 7. AC- } 92390 \\
\text { 8. AC- } 92390 \\
\text { 9. butachlor } \\
\text { 10. benthiocarb } \\
\text { 11. oxadiazon } \\
\text { 12. propanil } \\
\text { 13. propanil + } 2,4-D \\
\text { 14. propanil + parathion metílico }\end{array}$ & $\begin{array}{c}- \\
- \\
0,75 \\
1,00 \\
1,50 \\
1,00 \\
2,00 \\
3,00 \\
2,05 \\
4,50 \\
1,00 \\
4,32 \\
2,88+0,36 \\
1,98+0,24\end{array}$ & $\begin{array}{r}412,50 \mathrm{a} \\
1777,78 \mathrm{~b} \\
2012,50 \mathrm{~b} \\
1922,22 \mathrm{~b} \\
1909,72 \mathrm{~b} \\
1794,44 \mathrm{~b} \\
1870,83 \mathrm{~b} \\
1816,67 \mathrm{~b} \\
2094,44 \mathrm{~b} \\
2080,56 \mathrm{~b} \\
2125,00 \mathrm{~b} \\
1608,33 \mathrm{~b} \\
1794,44 \mathrm{~b} \\
1416,67 \mathrm{~b}\end{array}$ \\
\hline $\begin{array}{l}\text { F. } \\
\text { D.M.S. (Tukey) } \\
\text { C.V. }\end{array}$ & & \\
\hline
\end{tabular}

curando diminuir os custos, vem sendo usada no Japão em aplicações dirigidas em pomares de citros (1), podendo ser uma mistura de utilidade para aplicação dirigidas em determinadas culturas.

A partir dos dados discutidos podem-se concluir que as plantas daninhas presentes na área afetaram a produção de arroz causando um decréscimo de $80,6 \%$ quando se compara a testemunha sem capina com o tratamento com a produção mais alta; os tratamentos em pós-emergência foram os melhores por controlarem as duas plantas daninhas que ocorreram em maior densidade (carrapicho-de-carneiro e falsa-dormideira); o tratamento de propanil + parathion metílico muito embora não tenha apresentado produção significativamente diferente dos demais, só poderia ser indicado após novos estudos em condições controladas.

\section{LTERATURA CITADA}

1. Anderson, P.W.. Weed Seience: principles.
West Publishing Company, New York, 1977. 598p.

2. Bhan, V.M. Singh, M. \& Maurya, R.A.. Weed Control in field crops at Pantuagar, India. Pans, London, 15(4):690-701, 1970.

3. Bonling, C.C. \& Hudgins, H.R.. The effect of inseticides on the selectivity of propanil in rice. Weeds 14(1):94-95, 1966.

4. Brandes, G.A.. Stam F-34 proved sucessful for grass and weed control in rice. Rice Journal $65(1): 8,10,12,37-39,1962$.

5. French, E.W. \& Gay, W.B.. Weed control in rice flelds. Weed Crops, London, 15(5):196206, 1963.

6. Hudgins, H.R. Chemical control of barnyardgrass in the Texas rice belt. Rice Journal, New Orleans, 64(4):14-35, 1961.

7. Kern, F.. Stam F-34, novo herbicida seletivo para arroz. B. Inst. Ecol. Exp. Agric., Rio de Janeiro, 23:119-123, 1962.

8. Leiderman, L.; Araujo, J.M.; Arruda, H.V. de; Santos, C.A.L.; Souza, D.M. de. Controle de ervas daninhas pelo Stam F-34 em arrozal sem irrigaçáo em diferentes espaçamentos de plantio. In: Seminário Bras, de Herbicidas e Ervas Daninhas, 5. ${ }^{\circ}$, Cruz das Almas, 1964. Resumos, p.81.

9. Mangoensoekardjo, S. \& Kadnan, N.. Weed Control in Upland rice with mixtures of propanil mand 2,4-D esters. In: Conference of the Asian-Pacinc Weed Seience Society, $3^{\text {rd }}$, Kuala Lampur, 1981. Proceedings p.7.

10. Oliveira, A. Controle do capim arroz com herbicidas. Lavoura Arrozeira, Porto Alegre, 18(206):5-9, 1964. 
11. Revelo, M.A.. Herbicides: technical advances achieved in Colombia. Asricultura Tropical, Bogotá, 21(11):693-698, 1965.

12. Santos, C.A.L. \& Grassi, N.. Emprego do herblcida penoxalin nas culturas de arroz e milho. O Biológico 42:98-107, 1976.

13. Smith Jr., R.J.. Control of grass and other weeds in rice with several herbicides. Rep.
Ark. Agric. Exp. Station, 167:1-37, 1968.

14. Souza, A.F.. Efeitos herbicidas de misturas de propanil e inseticida fosforado na cultura do arroz (Ortza sativa L.). ESALQ-Piracicaba, 1972 (Dissertaçáo de Mestrado). 70p.

15. Vega, M.R.. Control of weeds in upland rice. In: International Rice Research Conference, The Philippines, 1970. Anais p.14. 